\title{
Propensity score-matched analysis of adjuvant chemotherapy for stage I non-small cell lung cancer
}

\author{
Yasuhiro Tsutani, MD, PhD, ${ }^{a}$ Yoshihiro Miyata, $\mathrm{MD}, \mathrm{PhD},{ }^{\mathrm{a}}$ Kei Kushitani, $\mathrm{MD}, \mathrm{PhD},{ }^{\mathrm{b}}$ \\ Yukio Takeshima, $\mathrm{MD}, \mathrm{PhD},{ }^{\mathrm{b}}$ Masahiro Yoshimura, $\mathrm{MD}, \mathrm{PhD},{ }^{\mathrm{c}}$ and Morihito Okada, $\mathrm{MD}, \mathrm{PhD}^{\mathrm{a}}$
}

Objective: The aim of this study was to reevaluate the role of adjuvant chemotherapy for patients with stage I non-small cell lung cancer (NSCLC).

Methods: Data from 800 patients with completely resected pathologic stage I NSCLC who received adjuvant chemotherapy $(n=191)$ and those who did not $(n=609)$ were analyzed retrospectively and propensity scorematched pairs were determined.

\begin{abstract}
Results: Although recurrence-free survival (RFS) and overall survival (OS) were not significantly different between patients who received adjuvant chemotherapy and those who did not in the univariate analyses, multivariate Cox analyses demonstrated that adjuvant chemotherapy was an independent prognostic factor for RFS and OS $(P=.008$ and $P=.009$, respectively). In 159 propensity score-matched pairs, including variables such as age, gender, smoking history, comorbidity, postoperative complication, histology, size of the invasive component of the tumor, and status of lymphatic, vascular, and pleural invasion, RFS and OS were considerably better in patients who received adjuvant chemotherapy (5-year RFS rate, 79.8\%; 5-year OS rate, 89.3\%) than in those who did not (5-year RFS rate, 60.2\%; 5-year OS rate, 75.2\%). Patients who received adjuvant chemotherapy showed significantly better RFS than those who did not in the group with an invasive component larger than $2 \mathrm{~cm}(5$-year RFS rate, $74.4 \%$ vs $55.2 \% ; P=.015)$ or in those with positive lymphatic invasion (5-year RFS rate, $63.3 \%$ vs $44.8 \% ; P=.05)$.
\end{abstract}

Conclusions: Adjuvant chemotherapy is effective for patients with stage I NSCLC, particularly those with an invasive component larger than $2 \mathrm{~cm}$ or those with lymphatic invasion. (J Thorac Cardiovasc Surg 2014;148:1179-85)

Platinum-based adjuvant chemotherapy after surgical resection in patients with stage II to IIIA non-small cell lung cancer (NSCLC) is recognized as a standard treatment and is currently used. ${ }^{1-3}$ However, for patients with stage I NSCLC, the use of adjuvant chemotherapy remains controversial. From the subgroup analysis in a clinical trial for stage IB NSCLC, platinum-based adjuvant chemotherapy was suggested to benefit patients with tumors of 4 $\mathrm{cm}$ or greater. ${ }^{4}$ In addition, tegafur-uracil (UFT) significantly improves survival in patients with stage I NSCLC, particularly those with lung adenocarcinomas greater than $2 \mathrm{~cm}$, as revealed by randomized phase 3 trials and metaanalysis. $^{5-7}$ These reports suggest that a subgroup of selected patients with stage I NSCLC will benefit from adjuvant chemotherapy.

\footnotetext{
From the Departments of Surgical Oncology ${ }^{\mathrm{a}}$ and Pathology, ${ }^{\mathrm{b}}$ Hiroshima University, Hiroshima, Japan; and Department of Thoracic Surgery, ${ }^{\mathrm{c}}$ Hyogo Cancer Center, Akashi, Japan.

Disclosures: Authors have nothing to disclose with regard to commercial support.

Received for publication Feb 22, 2014; revisions received May 3, 2014; accepted for publication May 29, 2014; available ahead of print Aug 10, 2014.

Address for reprints: Morihito Okada, MD, PhD, Department of Surgical Oncology, Research Institute for Radiation Biology and Medicine, Hiroshima University,

1-2-3-Kasumi, Minami-ku, Hiroshima City, Hiroshima 734-0037, Japan (E-mail: morihito@hiroshima-u.ac.jp).

$0022-5223 / \$ 36.00$

Copyright $(2014$ by The American Association for Thoracic Surgery

http://dx.doi.org/10.1016/j.jtcvs.2014.05.084
}

The aim of this retrospective study was to reevaluate the role of adjuvant chemotherapy for patients with stage I NSCLC and define the type of patients who would benefit from this chemotherapy.

\section{PATIENTS AND METHODS \\ Patients}

A retrospective review of 914 consecutive cases of completely resected pathologic stage I NSCLC between July 1, 2002, and December 31, 2011, was conducted. All patients who were staged according to the TNM Classification of Malignant Tumours, 7th Edition, underwent curative R0 resections. ${ }^{8}$ The inclusion criteria included curative surgery without neoadjuvant chemotherapy or radiotherapy and a definitive histopathologic diagnosis of NSCLC. Patients with incompletely resected tumors (R1 or R2), multiple tumors, or previous lung surgery were excluded from the analysis. After excluding 114 ineligible patients, 800 patients were included in this study (Figure 1). Comorbidities were defined as low pulmonary function, diabetes mellitus, ischemic heart disease, hypertension, or other severe comorbidities. Segmentectomy with systematic lymph node dissection was considered in patients with a clinical stage IA tumor with ample surgical margins for complete removal. Wedge resection for tumors that consisted primarily of a ground-glass opacity component on high-resolution computed tomography (CT) was performed. During lobectomy or segmentectomy, more than 6 lymph nodes, including the hilar and mediastinal lymph nodes, were sampled. Lobectomy or segmentectomy was performed using the same approach: hybrid video-assisted thoracoscopy. ${ }^{9,10}$

Adjuvant chemotherapy was considered for patients who underwent a standard operation and whose postoperative Eastern Cooperative Oncology Group (ECOG) performance status was 0 or 1 and in whom the total tumor size exceeded $2 \mathrm{~cm}$. Performance status was determined by a physician. 


$$
\begin{aligned}
& \text { Abbreviations and Acronyms } \\
& \begin{aligned}
\mathrm{CI} & =\text { confidence interval } \\
\mathrm{CT} & =\text { computed tomography } \\
\mathrm{CTCAE}= & \text { Common Terminology Criteria for } \\
& \text { Adverse Events } \\
\mathrm{ECOG}= & \text { Eastern Cooperative Oncology Group } \\
\mathrm{EVG}= & \text { Elastic-Van Gieson } \\
\mathrm{HR} & =\text { hazard ratio } \\
\mathrm{NSCLC}= & \text { non-small cell lung cancer } \\
\mathrm{OS} & =\text { overall survival } \\
\text { RFS } & \text { recurrence-free survival } \\
\mathrm{UFT} & =\text { tegafur-uracil }
\end{aligned}
\end{aligned}
$$

The recommendation for adjuvant chemotherapy was made at a cancer board meeting where the pathologic findings were reported. Of the $800 \mathrm{pa}-$ tients, 191 received adjuvant chemotherapy and 609 did not. The chemotherapy regimen included cisplatin plus vinorelbine in 10 patients, carboplatin plus paclitaxel in 12, carboplatin plus VP-16 in 1, gemcitabine plus tegafur-gimeracil-oteracil potassium (TS-1) in 5, gemcitabine in 1 , UFT in 129, and TS-1 in 33 patients. This multicenter study was approved by the institutional review board; the requirement for informed consent from individual patients was waived for this retrospective analysis of a prospective database.

All patients who underwent lung resection were followed up from the day of surgery. Postoperative complications were defined as grade 2 or higher by the National Cancer Institute Common Terminology Criteria for Adverse Events (CTCAE) version 4.0. Postoperative follow-up procedures including physical examination, chest roentgenogram every 3 months, and chest and abdominal CT examinations every 6 months were performed for the first 2 years; thereafter, a physical examination and chest roentgenogram were performed every 6 months and a CT examination was performed annually.

\section{Pathologic Examination}

The size of the invasive component was defined as the maximum dimension of the invasive tumor component, excluding the lepidic growth component described previously. ${ }^{11}$ Lymphatic and vascular invasion was assessed by immunohistochemistry for D2-40, which stains the lymphatic ducts, and elastic Van Gieson (EVG) staining of the elastic fiber of the vessels. Lymphatic and vascular invasion was determined to be positive when the process of spreading through or penetration was detected as an extension of a malignant neoplasm. To evaluate pleural invasion, elastic tissue fibers were subjected to EVG staining. Pleural invasion was defined as positive if cancer had invaded beyond the elastic layer, including invasion into the visceral pleural surface or neighboring organs. Histologic examinations were determined by pathologists from each institution for the purpose of this study.

\section{Statistical Analysis}

Data are presented as the number $(\%)$ or the mean \pm standard deviation unless otherwise stated. The $\chi^{2}$ test for categorical variables was used to compare frequencies, and the Fisher exact test was applied to small samples in all cohorts. McNemar tests were used to analyze the propensity scorematched pairs; $t$ tests and Mann-Whitney $U$ tests were used to compare continuous variables in all cohorts. Wilcoxon tests were used to analyze propensity score-matched pairs. Recurrence-free survival (RFS) was defined as the time from the day of surgery until the first event (relapse or death from any cause) or last follow-up. Overall survival (OS) was defined as the time from the day of surgery until death from any cause or

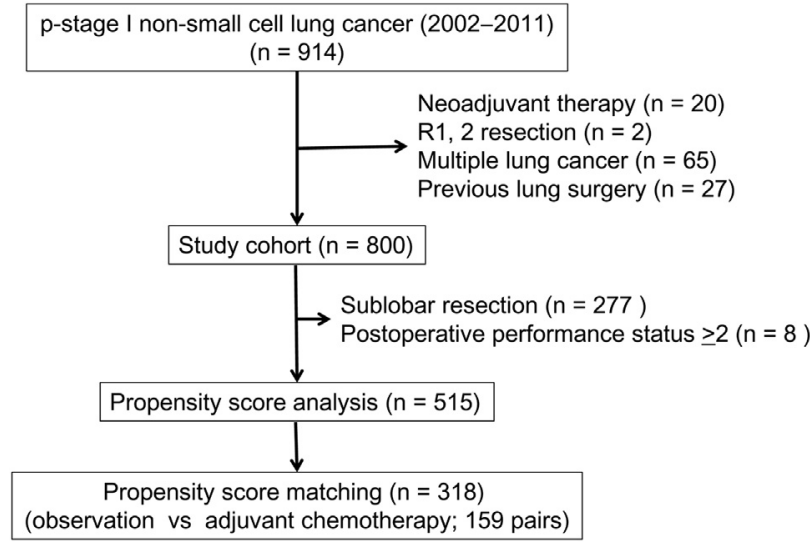

FIGURE 1. Flow chart for selection of patients for this study.

the last follow-up. The Kaplan-Meier method was used to analyze the duration of RFS and OS, and differences were assessed using the log-rank test. Multivariate analyses using the Cox proportional hazards models was used to assess the potential independent effects of adjuvant chemotherapy on RFS or OS. The following variables were included: age, gender, smoking history, comorbidity, procedure, performance status, postoperative complication, histology, size of the invasive component, status of lymphatic, vascular, and pleural invasion, and the use of adjuvant chemotherapy.

After excluding patients who had poor ECOG performance status $(\geq 2)$, and who underwent sublobar resection, propensity score matching was applied to balance the assignment of the patients and to correct for the presence of adjuvant chemotherapy, which confounded the survival calculations. The variables were age (continuous), gender, smoking history, comorbidity, postoperative complication, histology, size of the invasive component size (continuous), and status of lymphatic, vascular, and pleural invasion. Each variable was multiplied by a coefficient that was calculated using logistic regression analysis, and the sum of these values was taken as the propensity score for individual patients. The $\mathrm{C}$ statistic of the variables was 0.688 (95\% confidence interval $[\mathrm{CI}], 0.641-0.735, P<.0001)$. For matching, adjuvant chemotherapy and observation pairs with an equivalent propensity score were selected by a 1-to- 1 match with a caliper width of 0.2 of standard deviation. Statistical Package for the Social Sciences (SPSS) software (version 10.5; SPSS Inc, Chicago, Ill) was used to statistically analyze the data.

\section{RESULTS}

The characteristics of the 800 patients in the study are summarized in Table 1. The median follow-up period after surgery was 48.7 months, during which the tumor recurred in 128 patients. Of the 800 patients, 191 received adjuvant chemotherapy and 609 did not. Adjuvant chemotherapy was given significantly more often to male patients undergoing lobectomy, with a smoking history, without a postoperative complication, with a larger tumor size, larger invasive component, and lymphatic, vascular, and pleural invasion.

Taking all patients into account, there was no significant difference in the RFS and OS rates between patients who received adjuvant chemotherapy (5-year RFS rate, 78.1\%; 5-year OS rate, $88.1 \%$ ) and those who did not (5-year RFS rate, $71.5 \% ; P=.69 ; 5$-year OS rate, $81.5 \%$; 
TABLE 1. Patient characteristics

\begin{tabular}{|c|c|c|c|}
\hline & $\begin{array}{c}\text { Observation } \\
(n=609)\end{array}$ & $\begin{array}{c}\text { Adjuvant } \\
\text { chemotherapy } \\
(\mathrm{n}=191)\end{array}$ & $P$ value \\
\hline Age, $y \pm S D$ & $67.3 \pm 9.9$ & $66.3 \pm 9.5$ & .26 \\
\hline \multicolumn{4}{|l|}{ Gender, n $(\%)$} \\
\hline Male & $343(56.3)$ & $126(66.0)$ & .019 \\
\hline \multicolumn{4}{|l|}{ Smoking history, n (\%) } \\
\hline Yes & $322(52.9)$ & $119(62.3)$ & .024 \\
\hline \multicolumn{4}{|l|}{ Comorbidity, n (\%) } \\
\hline Yes & $87(14.3)$ & $36(18.8)$ & .14 \\
\hline Procedure, n (\%) & & & $<.001$ \\
\hline Lobectomy & $344(56.5)$ & $179(93.7)$ & \\
\hline Segmentectomy & $173(28.4)$ & $10(5.2)$ & \\
\hline Wedge resection & $92(15.1)$ & $2(1.0)$ & \\
\hline \multicolumn{4}{|l|}{$\begin{array}{l}\text { Performance status } \\
\text { (ECOG), } \mathrm{n}(\%)\end{array}$} \\
\hline$\geq 2$ & $12(2.0)$ & $2(1.0)$ & .54 \\
\hline \multicolumn{4}{|l|}{$\begin{array}{l}\text { Postoperative } \\
\quad \text { complication, } \mathrm{n}(\%)\end{array}$} \\
\hline Yes & $105(17.2)$ & $20(10.5)$ & .029 \\
\hline Histology, n (\%) & & & .99 \\
\hline Adenocarcinoma & $451(74.1)$ & $141(73.8)$ & \\
\hline Squamous cell carcinoma & $99(16.3)$ & $31(16.2)$ & \\
\hline Others & $59(9.7)$ & $19(10.0)$ & \\
\hline Total tumor size, $\mathrm{cm} \pm \mathrm{SD}$ & $2.2 \pm 0.9$ & $3.2 \pm 0.9$ & $<.001$ \\
\hline $\begin{array}{l}\text { Invasive tumor component } \\
\text { size, } \mathrm{cm} \pm \mathrm{SD}\end{array}$ & $1.7 \pm 1.2$ & $2.6 \pm 1.3$ & $<.001$ \\
\hline \multicolumn{4}{|l|}{ Lymphatic invasion, n (\%) } \\
\hline Positive & $126(20.7)$ & $65(34.0)$ & $<.001$ \\
\hline \multicolumn{4}{|l|}{ Vascular invasion, $\mathrm{n}(\%)$} \\
\hline Positive & $118(19.4)$ & $75(39.3)$ & $<.001$ \\
\hline \multicolumn{4}{|l|}{ Pleural invasion, $\mathrm{n}(\%)$} \\
\hline Positive & $90(14.8)$ & $60(31.4)$ & $<.001$ \\
\hline
\end{tabular}

$S D$, Standard deviation; $E C O G$, Eastern Cooperative Oncology Group.

$P=.17$; Figure 2). However, multivariate Cox analyses demonstrated that adjuvant chemotherapy was an independent prognostic factor of RFS (hazard ratio [HR], 0.58;
95\% CI, 0.39-0.87; $P=.008)$ and OS (HR, 0.47; $95 \%$ CI, $0.27-0.83 ; P=.009)$ as were age, gender, comorbidity, performance status, histology, size of the invasive component, and lymphatic and vascular invasion (Table 2).

When propensity score matching was used and variables such as age, gender, smoking history, comorbidity, postoperative complication, histology, size of the invasive component, and lymphatic, vascular, and pleural invasion were included, adjuvant chemotherapy and observation pairs were well matched (159 patients each), without significant differences in clinical and pathologic factors (Table 3). Among propensity score-matched pairs, patients who received adjuvant chemotherapy showed better RFS and OS rates (5-year RFS rate, 79.8\%, 5-year OS rate, $89.3 \%$ ) than those who did not (5-year RFS rate, $62.0 \%$; 5-year OS rate, 75.2\%; Figure 3).

Among all patients, those who received adjuvant chemotherapy showed significantly better RFS rates than those who did not in the group with an invasive component size greater than $2 \mathrm{~cm}$ (5-year RFS rate, $74.4 \%$ vs $55.2 \%$; $P=.015)$ or in those with positive lymphatic invasion (5-year RFS rate, $63.3 \%$ vs $44.8 \% ; P=.05$ ); no difference was observed in the group with invasive component size of $2 \mathrm{~cm}$ or less (5-year RFS rate, $78.9 \%$ vs $81.4 \% ; P=.90$ ) or in those with negative lymphatic invasion (5-year RFS rate, $85.4 \%$ vs $79.5 \% ; P=.78$; Figure 4 ). The 5 -year RFS rates of patients who received adjuvant chemotherapy and those who did not were $78.6 \%$ and $57.7 \%, P=.023$, in the subgroup with an invasive component size of 2 to $3 \mathrm{~cm}$, and $71.3 \%$ and $51.3 \%, P=.15$, in the subgroup with an invasive component size of 3 to $5 \mathrm{~cm}$, respectively. There was no difference in the RFS rates between patients who received adjuvant chemotherapy and those who did not in the groups divided by age, gender, smoking history, comorbidity, performance status, postoperative complication, histology, vascular, and pleural invasion. Among patients
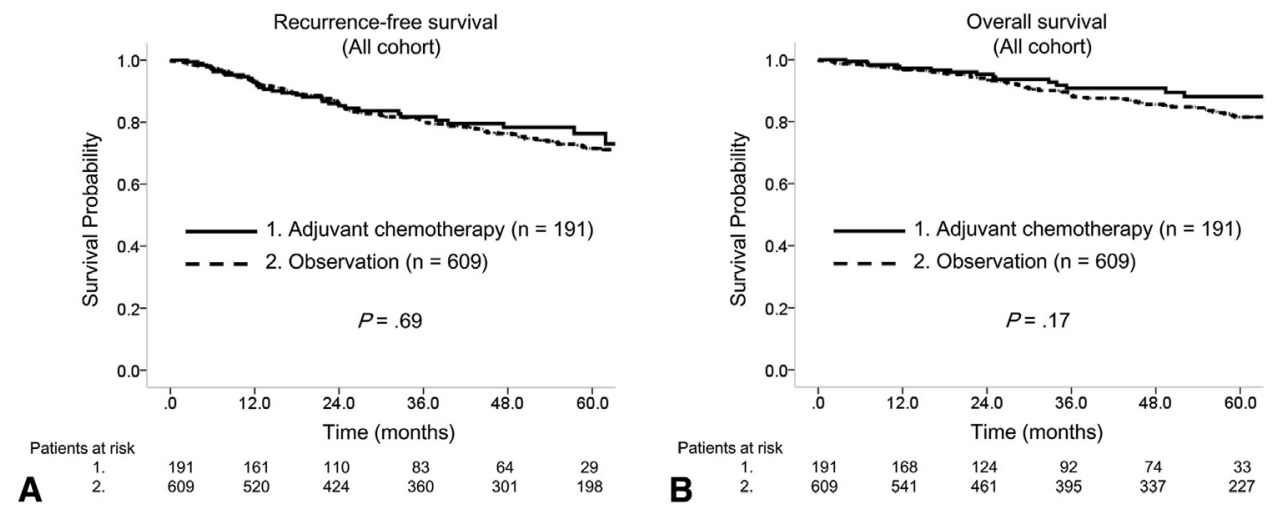

FIGURE 2. A, In all patients, there was no significant difference in the recurrence-free survival (RFS) rates between patients who received adjuvant chemotherapy (5-year RFS rate, 76.3\%; mean RFS rate, 78.1 months; 95\% confidence interval [CI], 70.5-85.8 months) and those who did not (5-year RFS rate, $71.5 \%$; mean RFS rate, 80.8 months; $95 \%$ CI, 77.5-84.0 months; $P=.69)$. B, In all patients, there was no significant difference in the overall survival (OS) rates between patients who received adjuvant chemotherapy (5-year OS rate, 88.1\%; mean OS rate, 89.6 months; 95\% CI, 83.6-95.5 months) and those who did not (5-year OS rate, 71.5\%; mean OS rate, 81.5 months; 95\% CI, 88.0-90.8 months; $P=.17$ ). 
TABLE 2. Multivariate Cox analyses for recurrence-free survival and overall survival

\begin{tabular}{|c|c|c|c|}
\hline & HR & $95 \% \mathrm{CI}$ & $P$ value \\
\hline \multicolumn{4}{|c|}{ Multivariate analysis of recurrence-free survival } \\
\hline Age & 1.04 & $1.02-1.05$ & $<.001$ \\
\hline \multicolumn{4}{|l|}{ Gender } \\
\hline Male (vs female) & 1.73 & $1.10-2.73$ & .018 \\
\hline \multicolumn{4}{|l|}{ Smoking history } \\
\hline Yes & 0.88 & $0.57-1.36$ & .58 \\
\hline \multicolumn{4}{|l|}{ Comorbidity } \\
\hline Yes & 1.49 & $0.99-2.24$ & .056 \\
\hline \multicolumn{4}{|l|}{ Procedure } \\
\hline Lobectomy (vs sublobar resection) & 0.92 & $0.64-1.32$ & .65 \\
\hline \multicolumn{4}{|l|}{ Performance status } \\
\hline$\geq 2$ & 15.8 & $7.87-31.5$ & $<.001$ \\
\hline \multicolumn{4}{|l|}{ Postoperative complication } \\
\hline Yes & 1.26 & $0.86-1.83$ & .23 \\
\hline \multicolumn{4}{|l|}{ Histology } \\
\hline $\begin{array}{l}\text { Adenocarcinoma } \\
\text { (vs nonadenocarcinoma) }\end{array}$ & 0.96 & $0.68-1.35$ & .80 \\
\hline Invasive tumor component size & 1.29 & $1.22-1.49$ & .001 \\
\hline \multicolumn{4}{|l|}{ Lymphatic invasion } \\
\hline Positive & 2.23 & $1.57-3.16$ & $<.001$ \\
\hline \multicolumn{4}{|l|}{ Vascular invasion } \\
\hline Positive & 1.80 & $1.23-2.64$ & .003 \\
\hline \multicolumn{4}{|l|}{ Pleural invasion } \\
\hline Positive & 1.07 & $0.74-1.55$ & .71 \\
\hline \multicolumn{4}{|l|}{ Adjuvant chemotherapy } \\
\hline Yes & 0.58 & $0.39-0.87$ & .008 \\
\hline \multicolumn{4}{|l|}{ Multivariate analysis of overall survival } \\
\hline Age & 1.06 & $1.03-1.08$ & $<.001$ \\
\hline \multicolumn{4}{|l|}{ Gender } \\
\hline Male (vs female) & 1.85 & $1.04-3.31$ & .037 \\
\hline \multicolumn{4}{|l|}{ Smoking history } \\
\hline Yes & 1.06 & $0.62-1.79$ & .84 \\
\hline \multicolumn{4}{|l|}{ Comorbidity } \\
\hline Yes & 1.86 & $1.15-3.03$ & .012 \\
\hline \multicolumn{4}{|l|}{ Procedure } \\
\hline Lobectomy (vs sublobar resection) & 1.07 & $0.68-1.67$ & .78 \\
\hline \multicolumn{4}{|l|}{ Performance status } \\
\hline$\geq 2$ & 12.4 & $5.81-26.5$ & $<.001$ \\
\hline \multicolumn{4}{|l|}{ Postoperative complication } \\
\hline Yes & 1.21 & $0.77-1.89$ & .42 \\
\hline \multicolumn{4}{|l|}{ Histology } \\
\hline $\begin{array}{l}\text { Adenocarcinoma } \\
\text { (vs nonadenocarcinoma) }\end{array}$ & 0.99 & $0.66-1.51$ & .98 \\
\hline Invasive tumor component size & 1.23 & $1.02-1.57$ & .031 \\
\hline \multicolumn{4}{|l|}{ Lymphatic invasion } \\
\hline Positive & 1.86 & $1.29-2.91$ & .006 \\
\hline \multicolumn{4}{|l|}{ Vascular invasion } \\
\hline Positive & 1.99 & $1.23-3.20$ & .005 \\
\hline Pleural invasion & & & \\
\hline Positive & 0.88 & $0.55-1.39$ & .58 \\
\hline Adjuvant chemotherapy & & & \\
\hline Yes & 0.47 & $0.27-0.83$ & .009 \\
\hline
\end{tabular}

$H R$, Hazard ratio; $C I$, confidence interval.
TABLE 3. Propensity score-matched comparison of clinical and pathologic factors between patients who received adjuvant chemotherapy and those who did not

\begin{tabular}{|c|c|c|c|}
\hline & $\begin{array}{c}\text { Observation } \\
(\mathbf{n}=\mathbf{1 5 9}) \\
\end{array}$ & $\begin{array}{c}\text { Adjuvant } \\
\text { chemotherapy } \\
(n=159) \\
\end{array}$ & $P$ value \\
\hline Age, $y \pm S D$ & $67.2 \pm 9.8$ & $66.4 \pm 9.2$ & .44 \\
\hline \multicolumn{4}{|l|}{ Gender, n (\%) } \\
\hline Male & $100(62.9)$ & $102(64.2)$ & .91 \\
\hline \multicolumn{4}{|l|}{$\begin{array}{l}\text { Performance status } \\
\text { (ECOG), n (\%) }\end{array}$} \\
\hline 0 or 1 & $159(100)$ & $159(100)$ & 1.0 \\
\hline \multicolumn{4}{|l|}{ Smoking history, n (\%) } \\
\hline Yes & $91(57.2)$ & $96(60.4)$ & .65 \\
\hline \multicolumn{4}{|l|}{ Comorbidity, n (\%) } \\
\hline Yes & $29(18.2)$ & $26(16.4)$ & .77 \\
\hline \multicolumn{4}{|l|}{ Procedure, n (\%) } \\
\hline Lobectomy & $159(100)$ & $159(100)$ & 1.0 \\
\hline \multicolumn{4}{|l|}{$\begin{array}{l}\text { Postoperative } \\
\text { complication, n (\%) }\end{array}$} \\
\hline Yes & $18(11.3)$ & $18(11.3)$ & 1.0 \\
\hline Histology, n (\%) & & & .60 \\
\hline Adenocarcinoma & $118(74.2)$ & $113(71.1)$ & \\
\hline Squamous cell carcinoma & $25(15.7)$ & $29(18.2)$ & \\
\hline Others & $16(10.1)$ & $17(10.7)$ & \\
\hline Tumor size, $\mathrm{cm} \pm \mathrm{SD} *$ & $2.5 \pm 1.2$ & $2.6 \pm 1.3$ & .63 \\
\hline \multicolumn{4}{|l|}{ Lymphatic invasion, $\mathrm{n}(\%)$} \\
\hline Positive & $51(32.1)$ & $48(30.2)$ & .78 \\
\hline \multicolumn{4}{|l|}{ Vascular invasion, $\mathrm{n}(\%)$} \\
\hline Positive & $54(34.0)$ & $55(34.6)$ & 1.0 \\
\hline \multicolumn{4}{|l|}{ Pleural invasion, n (\%) } \\
\hline Positive & $40(25.2)$ & $40(25.2)$ & 1.0 \\
\hline
\end{tabular}

who underwent sublobar resection, those who received adjuvant chemotherapy had significantly worse RFS (Table 4).

In the multivariate Cox analyses, adjuvant chemotherapy was identified as an independent favorable prognostic factor for RFS among patients with invasive component size greater than $2 \mathrm{~cm}$ or positive lymphatic invasion, but not among those with invasive component size of $2 \mathrm{~cm}$ or less and negative lymphatic invasion (Table 5).

\section{DISCUSSION}

Although there was no difference in the RFS and OS rates between patients who received adjuvant chemotherapy and those who did not in the univariate analyses, multivariate analyses demonstrated that adjuvant chemotherapy was an independent favorable prognostic factor for patients with stage I NSCLC. This discrepancy may be a result of differences in the background characteristics of patients who received adjuvant chemotherapy and those who did not. 

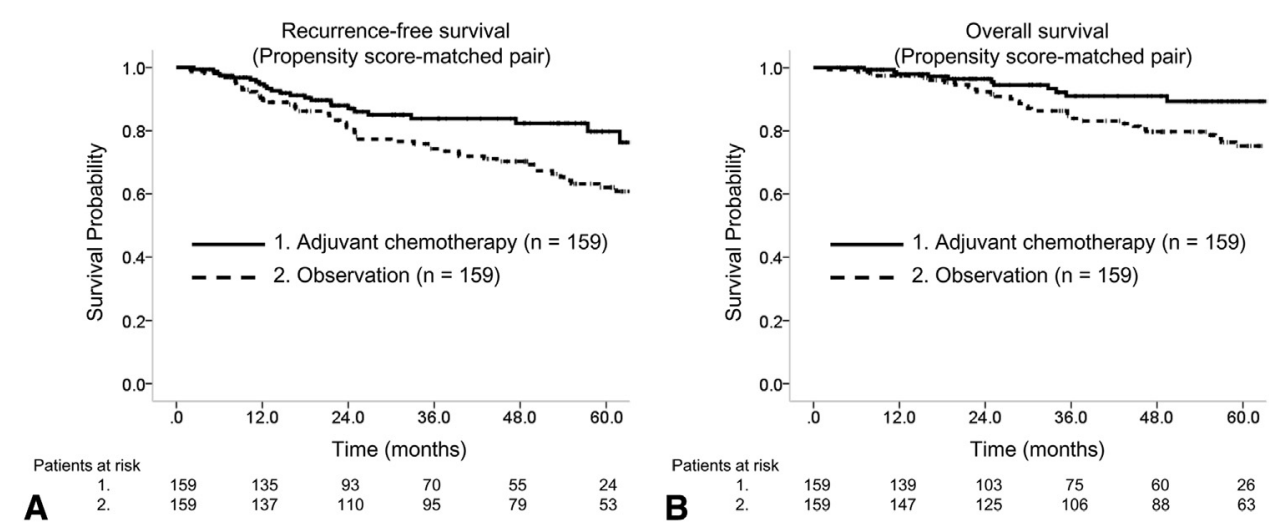

FIGURE 3. A, In propensity score-matched pairs, 5-year recurrence-free survival (RFS) rates of $79.8 \%$ (mean RFS rate, 80.8 months; $95 \%$ confidence interval [CI], 72.8-88.7 months) and 62.0\% (mean RFS rate, 68.9 months; 95\% CI, 62.7-75.0 months) were identified for patients who received adjuvant chemotherapy and those who did not, respectively. B, In propensity score-matched pairs, 5-year overall survival (OS) rates of $89.3 \%$ (mean OS rate, 89.8 months; 95\% CI, 82.9-96.7 months) and 75.2\% (mean OS rate, 82.2 months; 95\% CI, 76.4-88.1 months) were identified for patients who received adjuvant chemotherapy and those who did not, respectively.
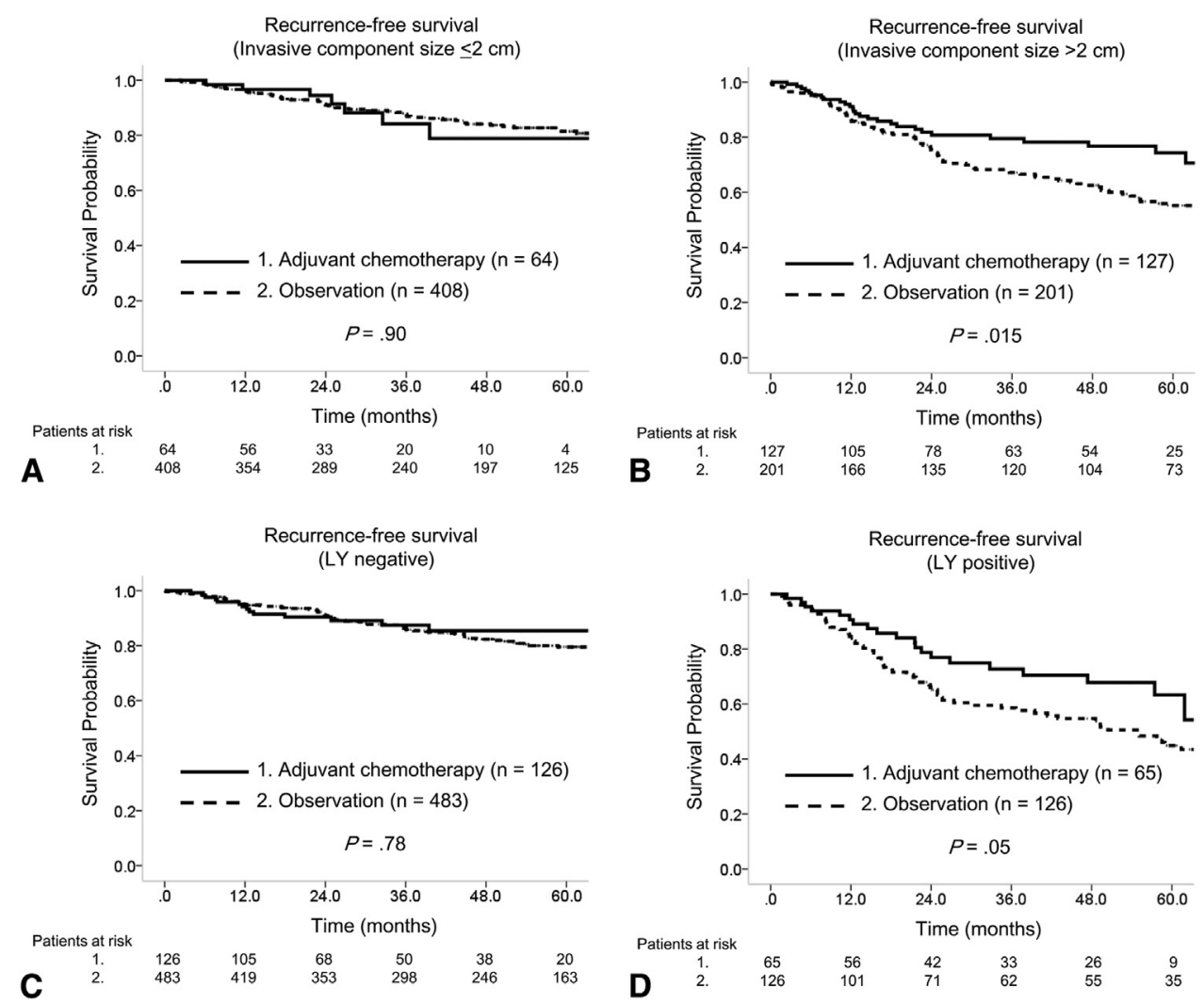

FIGURE 4. A, There was no difference in the recurrence-free survival (RFS) rate between patients who received adjuvant chemotherapy and those who did not in the group with an invasive component size $\leq 2 \mathrm{~cm}$ : 5-year RFS rate, 78.9\% (mean RFS rate, 85.1 months; 95\% confidence interval [CI], 74.3-95.8 months) versus $81.4 \%$ (mean RFS rate, 89.2 months; $95 \% \mathrm{CI}$, 85.7-92.7 months; $P=.90$ ). B, There was a significant difference in the RFS rate between patients who received adjuvant chemotherapy and those who did not in the group with an invasive component size $>2.0 \mathrm{~cm}$ : 5 -year RFS rate, $74.4 \%$ (mean RFS rate, 74.0 months; 95\% CI, 65.6-82.3 months) versus 55.2\% (mean RFS rate, 64.0 months; 95\% CI, 58.5-69.5 months; $P=.015$ ). C, There was no difference in the RFS rate between patients who received adjuvant chemotherapy and those who did not in the group without lymphatic invasion: 5-year RFS rate, $85.4 \%$ (mean RFS rate, 83.9 months; $95 \%$ CI, 74.1-93.7 months) versus 79.5\% (mean RFS rate, 87.5 months; 95\% CI, 84.2-90.7 months; $P=.78$ ). D, There was a significant difference in the RFS rate between patients who received adjuvant chemotherapy and those who did not in the group with lymphatic invasion: 5-year RFS rate, 63.3\% (mean RFS rate, 62.7 months; 95\% CI, 53.5-71.8 months) versus 44.8\% (mean RFS rate, 57.4 months; $95 \%$ CI, $49.8-65.0$ months; $P=.05)$. $L Y$, Positive lymphatic invasion. 
TABLE 4. Comparison of recurrence-free survival between patients who received adjuvant chemotherapy and those who did not in each subgroup based on the clinicopathologic factors

\begin{tabular}{|c|c|c|c|}
\hline & \multicolumn{2}{|c|}{ 5-y recurrence-free survival $(\%)$} & \multirow[b]{2}{*}{$P$ value } \\
\hline & Observation & $\begin{array}{c}\text { Adjuvant } \\
\text { chemotherapy }\end{array}$ & \\
\hline \multicolumn{4}{|l|}{ Age } \\
\hline$\leq 68 \mathrm{y}$ & 78.1 & 83.3 & .38 \\
\hline$>68 \mathrm{y}$ & 64.6 & 69.4 & .84 \\
\hline \multicolumn{4}{|l|}{ Gender } \\
\hline Male & 62.5 & 73.2 & .16 \\
\hline Female & 83.4 & 85.0 & .64 \\
\hline \multicolumn{4}{|l|}{ Smoking history } \\
\hline No & 82.0 & 80.9 & .25 \\
\hline Yes & 62.2 & 75.3 & .08 \\
\hline \multicolumn{4}{|l|}{ Comorbidity } \\
\hline No & 72.1 & 77.7 & .61 \\
\hline Yes & 68.8 & 76.2 & .82 \\
\hline \multicolumn{4}{|l|}{ Procedure } \\
\hline Sublobar resection & 74.3 & 47.1 & .036 \\
\hline Lobectomy & 69.5 & 79.0 & .16 \\
\hline \multicolumn{4}{|l|}{ Performance status } \\
\hline$<2$ & 72.9 & 76.6 & .94 \\
\hline$\geq 2$ & 8.3 & 50.0 & .31 \\
\hline \multicolumn{4}{|c|}{ Postoperative complication } \\
\hline No & 73.9 & 78.5 & .84 \\
\hline Yes & 60.7 & 59.2 & .78 \\
\hline \multicolumn{4}{|l|}{ Histology } \\
\hline Adenocarcinoma & 75.5 & 80.4 & .62 \\
\hline Nonadenocarcinoma & 60.6 & 65.1 & .92 \\
\hline \multicolumn{4}{|c|}{ Invasive component tumor size } \\
\hline$\leq 2 \mathrm{~cm}$ & 81.4 & 78.9 & .90 \\
\hline$>2 \mathrm{~cm}$ & 55.2 & 74.4 & .015 \\
\hline \multicolumn{4}{|l|}{ Lymphatic invasion } \\
\hline Negative & 79.5 & 85.4 & .78 \\
\hline Positive & 44.8 & 63.3 & .05 \\
\hline \multicolumn{4}{|l|}{ Vascular invasion } \\
\hline Negative & 77.7 & 89.0 & .13 \\
\hline Positive & 47.1 & 60.5 & .19 \\
\hline \multicolumn{4}{|l|}{ Pleural invasion } \\
\hline Negative & 74.8 & 86.6 & .09 \\
\hline Positive & 53.6 & 57.8 & .93 \\
\hline
\end{tabular}

Propensity score-matching analysis allowed us to compare survival among patients with similar background characteristics. Because the pathologic size of the invasive component reflects the malignancy grade and prognosis considerably better than the total tumor size in patients with early lung adenocarcinoma, ${ }^{11,12}$ we included the size of the invasive component instead of the total size of the tumor in the propensity score analysis. When potentially confounding variables such as age, gender, smoking history, comorbidity, postoperative complication, histology, size of the invasive component, and status of lymphatic, vascular, and pleural invasion were matched, patients who received adjuvant chemotherapy had considerably better RFS and OS rates than those who did not. These results strongly suggest that adjuvant chemotherapy is effective for selected patients with stage I NSCLC.

Although there is no definite consensus on the use of adjuvant chemotherapy for stage I NSCLC, platinumbased adjuvant chemotherapy was effective in patients with larger tumor size, poorly differentiated cancer, and good performance status. ${ }^{4,13}$ In Japanese patients, oral UFT was effective for patients with stage I NSCLC, particularly when the tumor was $2 \mathrm{~cm}$ or larger. ${ }^{5-7}$ Because of the heterogeneity of stage I NSCLC, selecting optimal candidates for adjuvant chemotherapy would be the appropriate strategy. In this study, we defined patients who would benefit from adjuvant chemotherapy. In patients with a tumor in which the size of the invasive component is more than $2 \mathrm{~cm}$ or with accompanying lymphatic invasion, adjuvant chemotherapy provides significantly better RFS rates than observation alone. In contrast, there is no significant difference in the RFS rates between patients who received adjuvant chemotherapy and those who did not among patients with an invasive component of $2 \mathrm{~cm}$ or less or without lymphatic invasion. In the subgroups stratified by age, gender, smoking history, histology, vascular, or pleural invasion, we could not identify patients who benefited from adjuvant chemotherapy. Therefore, the size of the invasive component and lymphatic invasion are predictive factors for the outcome of adjuvant chemotherapy as well as prognostic factors for RFS and OS in patients with stage I NSCLC. These findings were also supported by multivariate Cox analyses based on the subgroups for invasive component size and lymphatic invasion status.

This study has some limitations. Because this was a retrospective study, patients who received adjuvant chemotherapy were possibly selected; therefore, we performed multivariate analyses and propensity score-matched analysis to eliminate the selection bias as much as possible. In addition, because the adjuvant chemotherapy regimens were not consistent in this study, we could not conclude which regimen had a benefit for patients with stage I NSCLC, although there was no significant difference in the RFS rates between patients who received platinumbased chemotherapy and those who received other chemotherapies (data not shown). Prospective studies comparing observation versus adjuvant chemotherapy or UFT versus platinum-based chemotherapy for patients with stage I NSCLC with a larger invasive component or lymphatic invasion are warranted.

In conclusion, adjuvant chemotherapy is effective for patients with stage I NSCLC. Patients with a tumor with an invasive component greater than $2 \mathrm{~cm}$ or lymphatic invasion may particularly benefit from adjuvant chemotherapy. 
TABLE 5. Multivariate Cox analysis for recurrence-free survival based on invasive tumor size or lymphatic invasion

\begin{tabular}{|c|c|c|c|c|c|c|c|c|}
\hline & \multicolumn{2}{|c|}{$\begin{array}{l}\text { Invasive tumor } \\
\text { size }<\mathbf{2} \mathbf{~ c m}\end{array}$} & \multicolumn{2}{|c|}{$\begin{array}{c}\text { Invasive tumor } \\
\text { size }>2 \mathrm{~cm}\end{array}$} & \multicolumn{2}{|c|}{$\begin{array}{c}\text { Lymphatic invasion } \\
\text { negative }\end{array}$} & \multicolumn{2}{|c|}{$\begin{array}{c}\text { Lymphatic invasion } \\
\text { positive }\end{array}$} \\
\hline & HR $(95 \%$ CI $)$ & $P$ value & HR $(95 \%$ CI $)$ & $P$ value & HR $(95 \%$ CI $)$ & $P$ value & HR $(95 \%$ CI $)$ & $P$ value \\
\hline Age & $1.05(1.02-1.08)$ & .004 & $1.04(1.01-1.07)$ & .002 & $1.05(1.02-1.08)$ & .001 & $1.23(0.99-1.06)$ & .060 \\
\hline \multicolumn{9}{|l|}{ Gender } \\
\hline Male & $2.73(1.25-5.94)$ & .012 & $1.25(0.72-2.18)$ & .43 & $1.23(0.67-2.24)$ & .51 & $2.58(1.30-5.10)$ & .007 \\
\hline \multicolumn{9}{|l|}{ Smoking history } \\
\hline Yes & $1.15(0.55-2.40)$ & .71 & $0.79(0.46-1.35)$ & .39 & $1.59(0.88-2.86)$ & .13 & $0.46(0.24-0.87)$ & .016 \\
\hline \multicolumn{9}{|l|}{ Comorbidity } \\
\hline Yes & $0.89(0.41-1.92)$ & .76 & $1.87(1.13-3.08)$ & .014 & $1.54(0.87-2.74)$ & .14 & $1.56(0.85-2.87)$ & .16 \\
\hline \multicolumn{9}{|l|}{ Procedure } \\
\hline Lobectomy & $0.74(0.44-1.25)$ & .26 & $1.04(0.60-1.82)$ & .88 & $1.12(0.68-1.85)$ & .66 & $0.82(0.47-1.43)$ & .47 \\
\hline \multicolumn{9}{|l|}{ Performance status (ECOG) } \\
\hline$\geq 2$ & $6.45(1.75-23.8)$ & .005 & $21.3(9.09-49.8)$ & $<.001$ & $16.0(7.20-35.5)$ & $<.001$ & $379.4(28.8-4992.5)$ & $<.001$ \\
\hline \multicolumn{9}{|l|}{ Postoperative complication } \\
\hline Yes & $1.35(0.71-2.54)$ & .36 & $1.18(0.74-1.90)$ & .49 & $1.49(0.92-2.41)$ & .11 & $1.15(0.61-2.14)$ & .67 \\
\hline \multicolumn{9}{|l|}{ Histology } \\
\hline Adenocarcinoma & $0.89(0.47-1.69)$ & .72 & $0.88(0.59-1.31)$ & .52 & $0.73(0.46-1.18)$ & .20 & $1.36(0.82-2.25)$ & .24 \\
\hline Size of invasive component & N/A & N/A & N/A & N/A & $1.30(1.07-1.58)$ & .010 & $1.24(0.97-1.57)$ & .080 \\
\hline \multicolumn{9}{|l|}{ Lymphatic invasion } \\
\hline Positive & $5.03(2.63-9.64)$ & $<.001$ & $1.72(1.14-2.61)$ & .010 & N/A & N/A & N/A & N/A \\
\hline \multicolumn{9}{|l|}{ Vascular invasion } \\
\hline Positive & $1.14(0.57-2.29)$ & .71 & $2.23(1.40-3.56)$ & .001 & $2.49(1.52-4.08)$ & $<.001$ & $1.52(0.90-2.58)$ & .12 \\
\hline \multicolumn{9}{|l|}{ Pleural invasion } \\
\hline Positive & $0.96(0.46-1.98)$ & .91 & $1.03(0.66-1.59)$ & .91 & $0.83(0.45-1.50)$ & .53 & $1.08(0.67-1.76)$ & .75 \\
\hline \multicolumn{9}{|l|}{ Adjuvant chemotherapy } \\
\hline Yes & $0.97(0.42-2.27)$ & .95 & $0.62(0.39-0.98)$ & .040 & $0.66(0.36-1.21)$ & .18 & $0.55(0.32-0.95)$ & .033 \\
\hline
\end{tabular}

$H R$, Hazard ratio; $C I$, confidence interval; ECOG, Eastern Cooperative Oncology Group; N/A, not available.

\section{References}

1. Arriagada R, Bergman B, Dunant A, Le Chevalier T, Pignon JP, Vansteenkiste J, et al. Cisplatin-based adjuvant chemotherapy in patients with completely resected non-small cell lung cancer. N Engl J Med. 2004;350:351-60.

2. Winton T, Livingston R, Johnson D, Rigas J, Johnston M, Butts C, et al. Vinorelbine plus cisplatin vs. observation in resected non-small cell lung cancer. $N$ Engl J Med. 2005;352:2589-97.

3. Douillard J, Rosell R, Delena M, Carpagnano F, Ramlau R, Gonzales-Larriba JL, et al. Adjuvant vinorelbine plus cisplatin versus observation in patients with completely resected stage IB-IIIA non-small cell lung cancer (Adjuvant Navelbine International Trialist Association [ANITA]): a randomized controlled trial. Lancet Oncol. 2006;7:719-27.

4. Strauss GM, Herndon JE II, Maddaus MA, Johnstone DW, Johnson EA, Harpole DH, et al. Adjuvant paclitaxel plus carboplatin compared with observation in stage IB non-small-cell lung cancer: CALGB 9633 with the cancer and Leukemia Group B, Radiation Therapy Oncology Group, and North Central Cancer Treatment Group study Groups. J Clin Oncol. 2008;26:5043-51.

5. Kato H, Ichinose Y, Ohta M, Hata E, Tsubota N, Tada H, et al. A randomized trial of adjuvant chemotherapy with uracil-tegafur for adenocarcinoma of the lung. $N$ Engl J Med. 2004;350:1713-21.

6. Hamada C, Tanaka F, Ohta M, Fujimura S, Kodama K, Imaizumi M, et al. Metaanalysis of postoperative adjuvant chemotherapy with tegafur-uracil in nonsmall-cell lung cancer. J Clin Oncol. 2005;23:4999-5006.

7. Hamada C, Tsuboi M, Ohta M, Fujimura S, Kodama K, Imaizumi M, et al. Effect of postoperative adjuvant chemotherapy with tegafur-uracil on survival in patients with stage IA non-small cell lung cancer: an exploratory analysis from a meta-analysis of six randomized control trials. J Thorac Oncol. 2009;4: 1511-6.

8. Goldstraw P, Crowley J, Chansky K, Giroux DJ, Groome PA, Rami-Porta R, et al International Association for the Study of Lung Cancer International Staging Committee; Participating Institutions. The IASLC Lung Cancer Staging Project: proposals for the revision of the TNM stage groupings in the forthcoming (seventh) edition of the TNM Classification of Malignant Tumours. J Thorac Oncol. 2007:2:706-14.

9. Okada M, Sakamoto T, Yuki T, Mimura T, Miyoshi K, Tsubota N. Hybrid surgical approach of video-assisted minithoracotomy for lung cancer: significance of direct visualization on quality of surgery. Chest. 2005;128:2696-701.

10. Okada M, Mimura T, Ikegaki J, Katoh H, Itoh H, Tsubota N. A novel videoassisted anatomic segmentectomy technique: selective segmental inflation via bronchofiberoptic jet followed by cautery cutting. J Thorac Cardiovasc Surg. 2007; 133:753-8

11. Tsutani Y, Miyata Y, Mimae T, Kushitani K, Takeshima Y, Yoshimura M, et al The prognostic role of pathologic invasive component size, excluding lepidic growth, in stage I lung adenocarcinoma. J Thorac Cardiovasc Surg. 2013;146: 580-5.

12. Yoshizawa A, Motoi N, Riely GJ, Sima CS, Gerald WL, Kris MG, et al. Impact of proposed IASLC/ATS/ERS classification of lung adenocarcinoma: prognostic subgroups and implications for further revision of staging based on analysis of 514 stage I cases. Mod Pathol. 2011;24:653-64.

13. Park SY, Lee JG, Kim J, Byun GE, Bae MK, Lee CY, et al. Efficacy of platinumbased adjuvant chemotherapy in T2aN0 stage IB non-small cell lung cancer J Cardiothorac Surg. 2013;8:151. 